\title{
Variação da composição e qualidade do leite em função do volume de produção, período do ano e sistemas de ordenha e de resfriamento
}

\section{Change in composition and quality of milk as a function of volume of production, year period and milking systems and cooling}

\author{
Loreno Egidio Taffarel ${ }^{1 *}$; Patricia Barcellos $\operatorname{Costa}^{2}$; Claudio Yuji Tsutsumi; \\ Elcio Silverio Klosowski²; Eduardo Fonseca Portugal ${ }^{3}$; Antonio Carlos Lins ${ }^{4}$
}

\section{Resumo}

\begin{abstract}
Objetivou-se verificar o efeito de três volumes mensais de venda de leite, meses do ano, tipos de resfriadores e sistemas de ordenha sobre o ponto de congelamento do leite, o percentual de gordura, a contagem de células somáticas (CCS) e a contagem bacteriana total (CBT) do leite oriundo de produtores de um laticínio do Oeste do Paraná. Avaliou-se doze meses para cada informação (volume, gordura, crioscopia, CCS e CBT) com um total de 7.105 registros. As amostras para as análises foram coletadas pelos transportadores de leite junto aos produtores. As informações foram classificadas pelos volumes mensais produzidos (até 4.500 litros, entre 4.500-15.000 litros e mais que 15.000 litros), pelos sistemas de ordenha (manual, balde ao pé, canalizado e com transferidor) e tipos de resfriadores (imersão, granel e freezer) utilizados por cada produtor. O leite oriundo de produtores com volumes superiores a quinze mil litros mensais possui menor ponto crioscópico, teor de gordura, CBT e CCS. Ocorreram variações estacionais do ponto de congelamento, teor de gordura, CBT e CCS. As variações da CBT durante os períodos do ano são menores no leite oriundo de resfriamento a granel e de ordenhadeiras canalizadas. Existem fatores relacionados ao manejo dos animais e higienização dos equipamentos de ordenha e resfriamento que necessitam ser trabalhados junto aos produtores.
\end{abstract}

Palavras-chave: Crioscopia, contagem bacteriana total, contagem de células somáticas, gordura

\begin{abstract}
Aimed to evaluate the effect of three volumes monthly milk sales, months of year, types of coolers and milking systems on the freezing point of milk, fat percentage, somatic cell count (SCC) and bacterial count Total (CBT) milk come from producers that sell to a dairy of Western of Paraná. We evaluated twelve months for volume, fat, freezing point, SCC and TBC with a total of 7,105 records. Samples for analysis were collected by milk transporters. The information was classified by monthly volume purchased from each producer (up to 4,500 gallons between 4,500-15,000 liters and more than 15,000 liters), by milking systems (manual, bucket foot, piped and protractor) and types of coolers (immersion
\end{abstract}

1 Médico Veterinário, M.e em Zootecnia, Dr. em Agronomia, Universidade Estadual do Oeste do Paraná, UNIOESTE, Marechal Cândido Rondon, PR. E-mail: loreno.taffarel@gmail.com

2 Profs., Centro de Ciências Agrárias, UNIOESTE, Marechal Cândido Rondon, PR. E-mail: patriciabarc@hotmail.com; cytsutsu@ uol.com.br; elciosk1@yahoo.com.br

3 Médico Veterinário, Responsável Técnico Unidade Laticínios Frimesa, Marechal Cândido Rondon, PR. E-mail: portugal@, frimesa.com.br

4 Técnico em Agropecuária e Graduado em Geografia, Fomento Leite Frimesa, Marechal Cândido Rondon, PR. E-mail: linsufq@ frimesa.com.br

* Autor para correspondência 
, bulk and freezer) used by each producer. The milk got of producers with volumes exceeding fifteen thousand liters per month has a freezing point and fat content lesser, but have a better CBT and CCS. There were seasonal variations of freezing point, fat, CBT and CCS. Variations of CBT during periods of the year are lower in milk derived from bulk cooling and milking piped system. There are factors related to handling and cleaning of milking equipment and cooling that need to be worked with the milk producers.

Key words: Crioscopia, fat, somatic cell count, total bacterial count

\section{Introdução}

Os mercados nacionais e internacionais são importantes motivadores que estimulam as indústrias lácteas a discutirem o pagamento do leite por qualidade (MARTINS et al., 2004). Entre os indicadores utilizados pelas indústrias para pagar por qualidade destacam-se a contagem de células somáticas (CCS), contagem bacteriana total (CBT) (TAKAHASHI et al., 2012), crioscopia ou ponto de congelamento (TRONCO, 1997) e o percentual de proteína e gordura (ROMA JÚNIOR et al., 2009).

A presença de microrganismos no úbere das vacas leva ao aumento da CCS (FAGAN et al., 2008). A CCS facilita a identificação de vacas com mastite subclínica e aparentemente sadias e isso pode levar a identificação de animais focos de contaminação, que são transmissores de infecção pela linha de ordenha ou pela mão do ordenhador, e essa condição contribui para menor qualidade do leite e perdas econômicas (BARBOSA; BENEDETI; GUIMARÃES, 2009).

As contaminações que causam mastite, elevando a contagem bacteriana total (CBT) e a CCS, em geral são provocadas por manejos inadequados de ordenha e do rebanho, e também por características dos tetos das vacas e pelo equipamento de ordenha (MEIN et al., 2004). Esses autores afirmaram que a dinâmica da interação entre teta $\mathrm{x}$ teteira pode levar a novas infecções do úbere.

Os principais fatores que levam a novas infecções causadas pelo equipamento de ordenha são as diferenças de pressão e o número de pulsações por minuto (ZECCONI et al., 2002), embora os relatos são de que os agentes ambientais são os responsáveis pela maior proporção de infecções mamárias e contaminações do leite (PYÖRÄLÄ, 2002). Não é necessariamente o tipo de ordenha o causador de infecções mamárias, mas o nível de higiene adotado e o manejo de cada propriedade, e isto está diretamente relacionado à CCS e CBT, que aumentam quando a higiene ou manejo são inadequados (BARBOSA; BENEDETI; GUIMARÃES, 2009).

Outros fatores também interferem sobre a CCS e CBT, como período do ano, ambiente, número de dias em lactação, volume de leite produzido por produtor relacionado à capacidade de resfriamento do leite considerando tempo $\mathrm{x}$ temperatura de armazenamento do leite e a higiene de ordenha (TAKAHASHI et al., 2012).

Já o índice crioscópico ou ponto de congelamento do leite é uma propriedade física que apresenta pouca variação, mas variações podem ocorrer devido modificações na dieta do rebanho leiteiro, bem como do período de lactação e estação do ano (TRONCO, 1997). A fraude por adição intencional de leite produz alterações significativas no ponto de congelamento e por isso esse índice é utilizado para identificar fraude por aguagem do leite "in natura" (TRONCO, 1997; BECCHI, 2003).

Limitar o acesso à ingestão de água durante as ordenhas, principalmente em períodos de elevadas temperaturas ambientaise compensar pelo livre acesso antes da ordenha, podem ser causasdealterações no índice crioscópico do leite (HENNO et al., 2008). Isso porque a estabilidade do ponto de congelamento é explicada com base no equilíbrio osmótico existente entre o leite, o sangueque circula na veia mamária, e a relação 
complementar entre a lactose e os cloretos contidos nos mesmos, não apenas durante sua síntese, mas durante todo o tempo em que o leite permanece no úbere (MONTIPÓ, 1992).

Outra característica do leite que os laticínios consideram para pagamento ao produtor é o teor de gordura, que pode ser influenciado pela alimentação, raça, período de lactação (RIBAS et al., 2004), proporção concentrado x volumoso (GONZALEZ; CAMPOS, 2003), além do tipo de ordenha (manual ou mecânica) e período de coleta (manhã ou tarde) (REIS et al., 2007) ou se a amostra foi coletada no início ou final da ordenha (TAVERNA, 2004).

Assim, o objetivo deste estudo foi verificar o efeito de três volumes mensais de venda de leite, meses do ano, tipos de resfriadores e sistemas de ordenha sobre o ponto de congelamento do leite, o percentual de gordura, a contagem de células somáticas (CCS) e a contagem bacteriana total (CBT).

\section{Material e Métodos}

Esta pesquisa foi realizada no Centro de Ciências Agrárias da Universidade Estadual do Oeste do Paraná (UNIOESTE), Campus de Marechal Cândido Rondon, PR, em parceria com uma indústria láctea da região Oeste do Paraná, que cedeu os dados de mensais de volume, percentual médio de gordura, crioscopia média, contagem de células somáticas (CCS), contagem bacteriana total (CBT) e sobre os tipos de resfriadores e sistemas de ordenhas utilizados pelos produtores. Os dados referem-se ao período de outubro de 2009 a setembro de 2010 e são oriundos de 602 produtores da microrregião de Marechal Cândido Rondon-PR. Os dados de temperaturas médias, máximas e mínimas e da precipitação total mensal desse período foram fornecidos pela Estação Automática de Marechal Cândido Rondon do IMMET (Código OMM86916) (Figura 1).

Figura 1. Temperaturas médias (média, máxima e mínima) e precipitação total mensal no período de outubro de 2009 a setembro de 2010 na microrregião de Marechal Cândido Rondon.

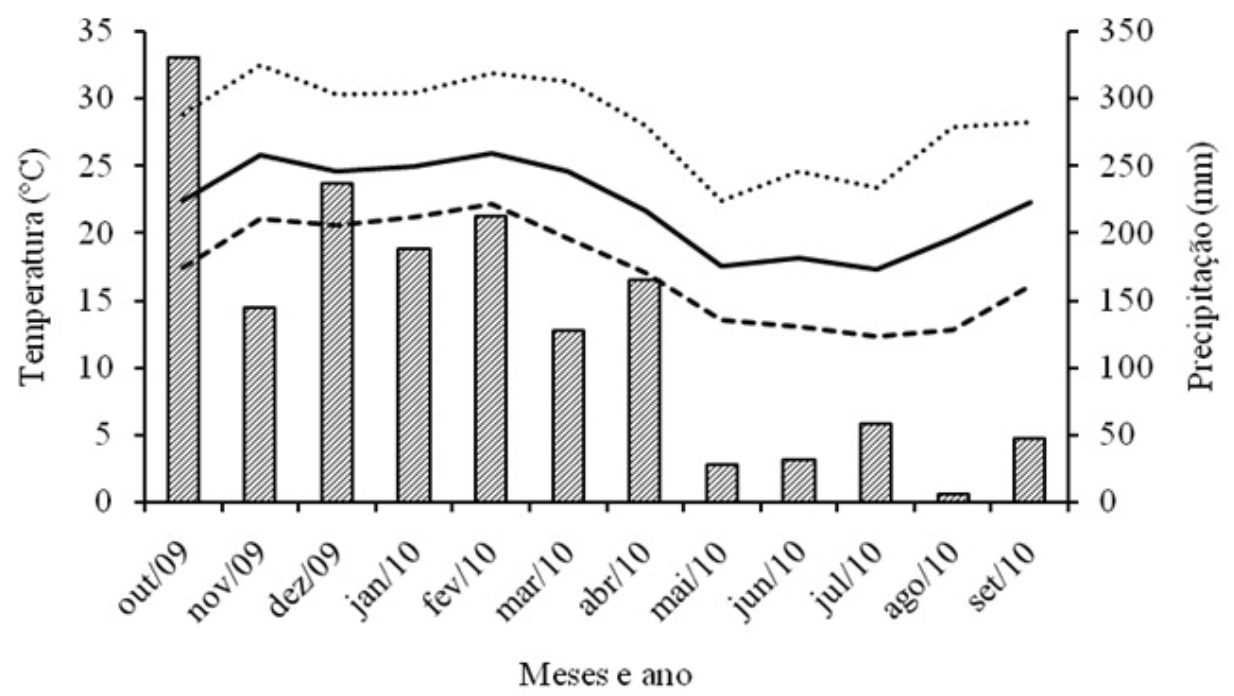

manaman Chuvas $(\mathrm{mm}) \longrightarrow$ Temp. Méd $\left({ }^{\circ} \mathrm{C}\right) \cdots \cdots \cdot$..... Temp. Máx $\left({ }^{\circ} \mathrm{C}\right)----$ Temp. Min $\left({ }^{\circ} \mathrm{C}\right)$

Fonte: Convênio INMET-Universidade Estadual do Oeste do Paraná.

O total de registros utilizados nos doze meses para cada informação (volume, gordura, crioscopia, CCS e CBT) foi de 7.105. As amostras para as análises foram realizadas pelos transportadores de leite junto aos produtores. Para CBT, na ocasião da coleta foram adicionados duas a três gotas do conservante 
azidiol por amostra. Para CCS cada frasco continha o conservante bronopol (2-bromo-2-nitropropano1,3-diol). Após as coletas, as amostras foram acondicionadas em caixas especiais e enviadas ao laboratório da Associação Paranaense de Criadores de Bovinos da Raça Holandesa (APCBRH) para realização das análises. As análises de crioscopia e gordura foram realizadas nos laboratórios do laticínio.

As informações foram classificadas pelo volume mensal comprado de cada produtor (até 4500 litros, entre 4500-15.000 litros e mais que 15.000 litros), pelos sistemas de ordenha (manual, balde ao pé, canalizado e com transferidor) e tipos de resfriadores (imersão, granel e freezer) utilizados por cada produtor.

Os dados foram analisados pelo programa SAS (SAS Institute, 2002) utilizando-se o procedimento proc GLM e foram consideradas as interações para todos os fatores analisados. Os dados médios foram apresentados considerando-se a interação como significativa.

\section{Resultados e Discussão}

$\mathrm{Na}$ Tabela 1 pode-se observar que dos 7.105 registros analisados no período de outubro de 2009 a setembro de 2010, 67,25\% das propriedades produziram até 4.500 litros por mês, ou seja, uma produção inferior a 150 litros diários. Dessas, $7,49 \%$ resfriam o leite com freezer, embora este equipamento não esteja previsto na legislação mas também foi relatado sua utilização por produtores na região Norte do Paraná por Vallin et al. (2009). A maioria das propriedades $(55,55 \%)$ resfriam o leite com resfriador do tipo imersão e $36,96 \%$ possuem resfriador a granel.

Tabela 1. Tipos de resfriadores de acordo com o volume mensal comercializado pelos produtores na microrregião de Marechal Cândido Rondon no período de outubro de 2009 a setembro de 2010.

\begin{tabular}{|c|c|c|c|c|c|c|c|c|}
\hline \multirow{2}{*}{ Volume/mês } & \multicolumn{6}{|c|}{ Resfriadores } & \multirow[b]{2}{*}{ Total } & \multirow[b]{2}{*}{$\%$} \\
\hline & Freezer & $\%$ & Imersão & $\%$ & Granel & $\%$ & & \\
\hline $0-4.500$ & 358 & 7,49 & 2654 & 55,55 & 1766 & 36,961 & 4778 & 67,25 \\
\hline $4.501-15.000$ & 0 & 0 & 405 & 21,65 & 1466 & 78,354 & 1871 & 26,33 \\
\hline$>15.000$ & 0 & 0 & 98 & 21,49 & 358 & 78,509 & 456 & 6,42 \\
\hline Total & 358 & 5,04 & 3157 & 44,43 & 3590 & 50,528 & 7105 & 100,00 \\
\hline
\end{tabular}

Fonte: Elaboração dos autores.

A faixa de produção entre 4.500 a 15.000 litros mensais representou $26,33 \%$ das propriedades, das quais $21,65 \%$ resfriam o leite com resfriadores do tipo imersão e outros 78,35\% resfriam o leite com resfriadores do tipo granel. Das propriedades com faixa de produção superior a 15.000 litros mensais, a distribuição sobre o tipo de resfriador utilizado é semelhante a faixa anterior, sendo que 21,49\% utilizam resfriador do tipo imersão e 78,51\% utilizam do tipo granel.
Os sistemas de ordenha utilizados estão demonstrados na Tabela 2. Entre os produtores com até 4.500 litros mensais, $4,12 \%$ realizam a ordenha de forma manual e a maioria com ordenhadeira do tipo balde ao pé $(89,56 \%)$, sendo que outros $5,69 \%$ com ordenha do tipo canalizada e outros $0,63 \%$ com ordenha do tipo com transferidor.

$\mathrm{Na}$ faixa de produção entre 4.500 a 15.000 litros mensais a maioria utiliza ordenhadeira do tipo balde ao pé $(56,87 \%)$, seguido pela ordenha canalizada 
$(31,91 \%)$ e outros $11,22 \%$ com transferidor. $\mathrm{Na} \quad 27,19 \%$ utilizam ordenhadeira do tipo balde ao pé faixa de produção superior a 15.000 litros mensais, e a maioria utiliza a ordenha canalizada $(63,60 \%)$, com outros $9,21 \%$ com transferidor.

Tabela 2. Sistemas de ordenha de acordo com o volume mensal comercializado pelos produtores na microrregião de Marechal Cândido Rondon no período de outubro de 2009 a setembro de 2010.

\begin{tabular}{cccccccccccc}
\hline & \multicolumn{10}{c}{ Ordenhadeiras } & \\
\cline { 2 - 8 } Volume/mês & Manual & $\%$ & Balde ao Pé & $\%$ & Canalizada & $\%$ & Transferidor & $\%$ & \multirow{2}{*}{ Total } & $\%$ \\
\hline $0-4.500$ & 197 & 4,12 & 4279 & 89,56 & 272 & 5,69 & 30 & 0,63 & 4778 & 67,25 \\
$4.501-15000$ & 0 & 0,00 & 1064 & 56,87 & 597 & 31,91 & 210 & 11,22 & 1871 & 26,33 \\
$>15.000$ & 0 & 0,00 & 124 & 27,19 & 290 & 63,60 & 42 & 9,21 & 456 & 6,42 \\
\hline Total & 197 & 2,77 & 5467 & 76,95 & 1159 & 16,3 & 282 & 3,97 & 7105 & 100,00 \\
\hline
\end{tabular}

Fonte: Elaboração dos autores.

Os produtores com produção superior a 15.000 litros mensais tiveram uma crioscopia menor no período estudado, em relação aos estratos com menor produção (Tabela 3). Os rebanhos da região Oeste do Paraná pastejam em sistemas de piqueteamento (76,7\%), rotação de pastagens $(58,9 \%)$ e $92,3 \%$ fazem suplementação alimentar com ração e grãos e a produtividade do rebanho é maior quando é utilizado ração na alimentação (IPARDES, 2009). Esses resultados estão de acordo com os relatados por Montipó (1992) que animais alimentados a base de grãos, animais estabulados e alimentados a pasto, e ração com baixos teores de carboidratos tendem a ter o ponto de congelamento se aproximando de zero.

Tabela 3. Estratificação do volume de produção mensal (L/mês), número de produtores, média da crioscopia, gordura, contagem bacteriana total (CBT) e da contagem de células somáticas (CCS).

\begin{tabular}{|c|c|c|c|c|}
\hline Produção $^{1}$ & Crioscopia & Gordura (\%) & $\mathrm{CBT}^{2}(\mathrm{UFC} / \mathrm{mL})$ & $\mathrm{CCS}(\mathrm{cel} / \mathrm{mL})$ \\
\hline $0-4500$ & 541,69 A & $3,5593 \mathrm{~A}$ & $4.089 \mathrm{~A}$ & 870.033 B \\
\hline $4500-15000$ & $541,22 \mathrm{~A}$ & $3,5395 \quad \mathrm{~B}$ & $2.036 \mathrm{~B}$ & $935.340 \quad \mathrm{~A}$ \\
\hline$>15000$ & $540,75 \quad$ B & 3,5359 В & $1.294 \mathrm{C}$ & 891.169 B \\
\hline $\mathrm{p}$ & 0,0001 & 0,0053 & 0,0001 & 0,0111 \\
\hline $\mathrm{CV}^{3}$ & 0,73 & 7,41 & 144,54 & 90,11 \\
\hline
\end{tabular}

${ }^{1}$ Produção em litros por mês por propriedade. ${ }^{2} \mathrm{CBT}=* 1000 .{ }^{3} \mathrm{CV}=$ coeficiente de variação

Fonte: Elaboração dos autores.

A análise estatística para crioscopia resultou em diferenças significativas para quantidade de litros comercializados $(p<0,0001)$ e períodos do ano $(p<0,0001)$, sendo que para a interação para período e volume o nível de significância foi $\mathrm{p}=0,0713$, e o coeficiente de variação (CV\%) foi de $72 \%$
(Figura 2). Isso significa que a causa da variação da crioscopia não é o volume mensal comercializado por cada produtor.

As principais causas do aumento do índice crioscópico (ponto de congelamento se aproximando de zero) estão às características relacionadas ao clima 
e época do ano, pois alteram o desenvolvimento vegetativo e a oferta de forrageiras, e com isso ocorre redução de energia, o que provoca redução da lactose no leite (BORGES; PINTO, 2007).

Figura 2. Crioscopia de acordo com o volume mensal no período de outubro de 2009 a setembro de 2010. (quantidade de litros $\mathrm{p}<0,0001$; períodos do ano $\mathrm{p}<0,0001$; interação quantidade $\mathrm{x}$ períodos $\mathrm{p}=0,0713 ; \mathrm{CV}=71,99 \%$ ).

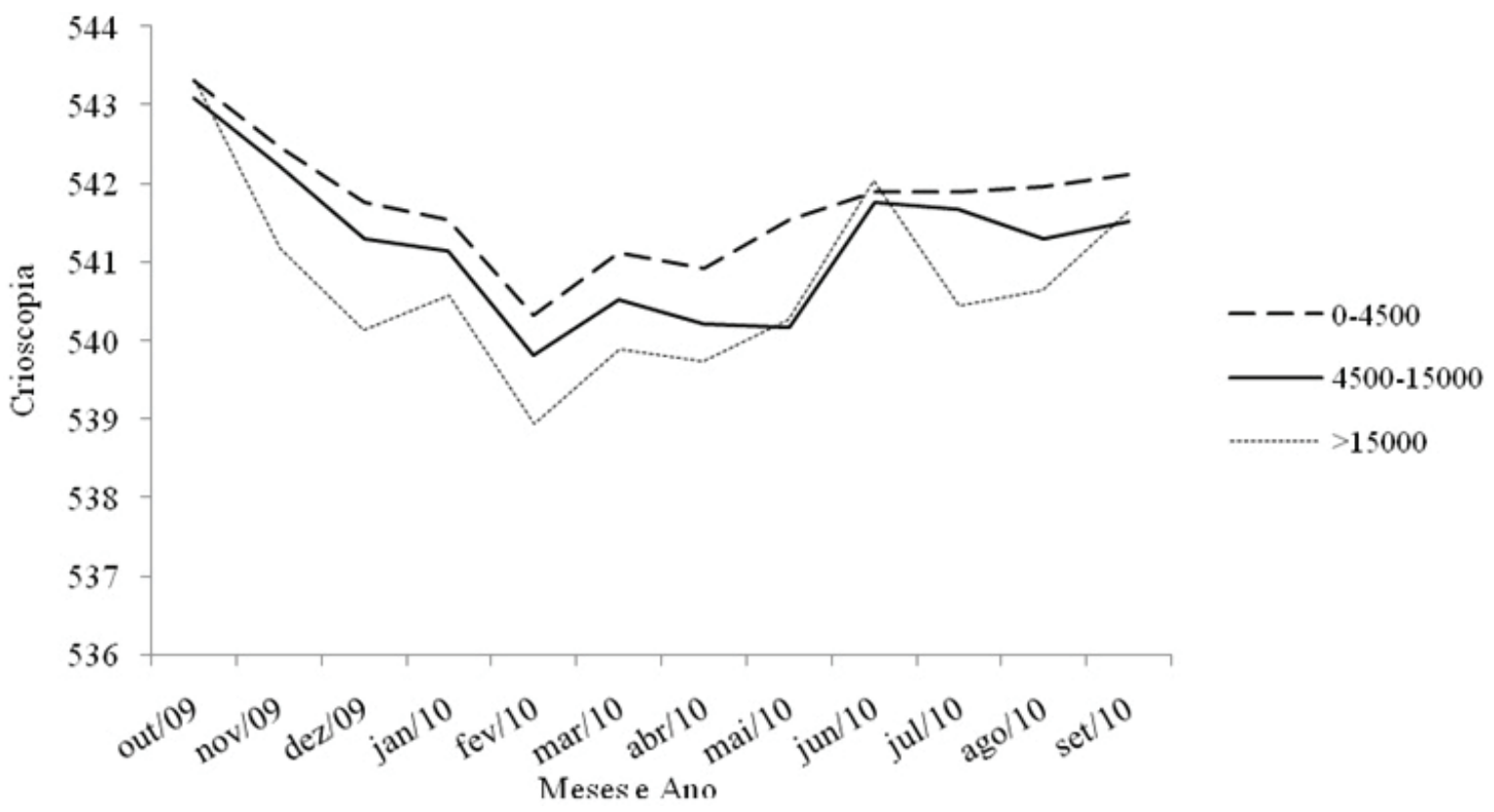

Fonte: Elaboração dos autores.

O índice crioscópico é bastante relacionado à lactose, cloretos e outros componentes solúveis em água; também o desequilíbrio entre energia e proteína na dieta, e a baixa eficiência de utilização de proteína dietética podem reduzir a síntese de proteína láctea e aumentar a crioscopia do leite, entretanto, de forma isolada, a nutrição e sazonalidade produzem os maiores desvios sobre o ponto de congelamento do leite (BOTARO; SANTOS, 2008).

Essas explicações podem justificar a significativa menor crioscopia no período de outono pela redução da oferta de forragem de verão e a consequente maior proporção de grãos na dieta. Também podem explicar a redução do índice de crioscopia nos meses de inverno (junho e julho) dos produtores com produção superior a 15.000 litros mensais, pela maior utilização de ração e pela oferta de pastagem de inverno (aveia) (Figura 2). Estas observações estão de acordo com aquelas observadas por Henno et al. (2008) que relataram maior crioscopia quando as vacas estavam no período de pastoreio do que quando estabuladas.

A análise estatística para gordura resultou significativa para interação quantidade de litros comercializados por mês e períodos do ano $(\mathrm{p}=0,0181)$ (Figura 3).

O percentual de gordura foi maior nos rebanhos com até 4500 litros mensais (Tabela 3). Ribas et al. (2004) destacaram a correlação negativa entre produção de leite por vaca e teor de gordura no leite em rebanhos do Estado do Paraná, salientando que a qualidade da forragem e da dieta interferem no percentual de gordura do leite. É possível que isso possa ser explicado pela maior produtividade (12,2 L/vaca/dia) dos rebanhos que consomem ração e que adotam alta e média tecnologia, o que 
representa 48,7\% e 33,9\%, respectivamente, da vacas leiteiras tende a reduzir o conteúdo de gordura produção leiteirano Oeste do Paraná (IPARDES, no leite de forma proporcional (GONZALEZ; 2009). A utilização de concentrados na dieta de CAMPOS, 2003).

Figura 3. Percentual de gordura de acordo com o volume mensal no período de outubro de 2009 a setembro de 2010 (interação quantidade de litros x períodos do ano $\mathrm{p}=0,0181 ; \mathrm{CV}=729,74 \%$ ).

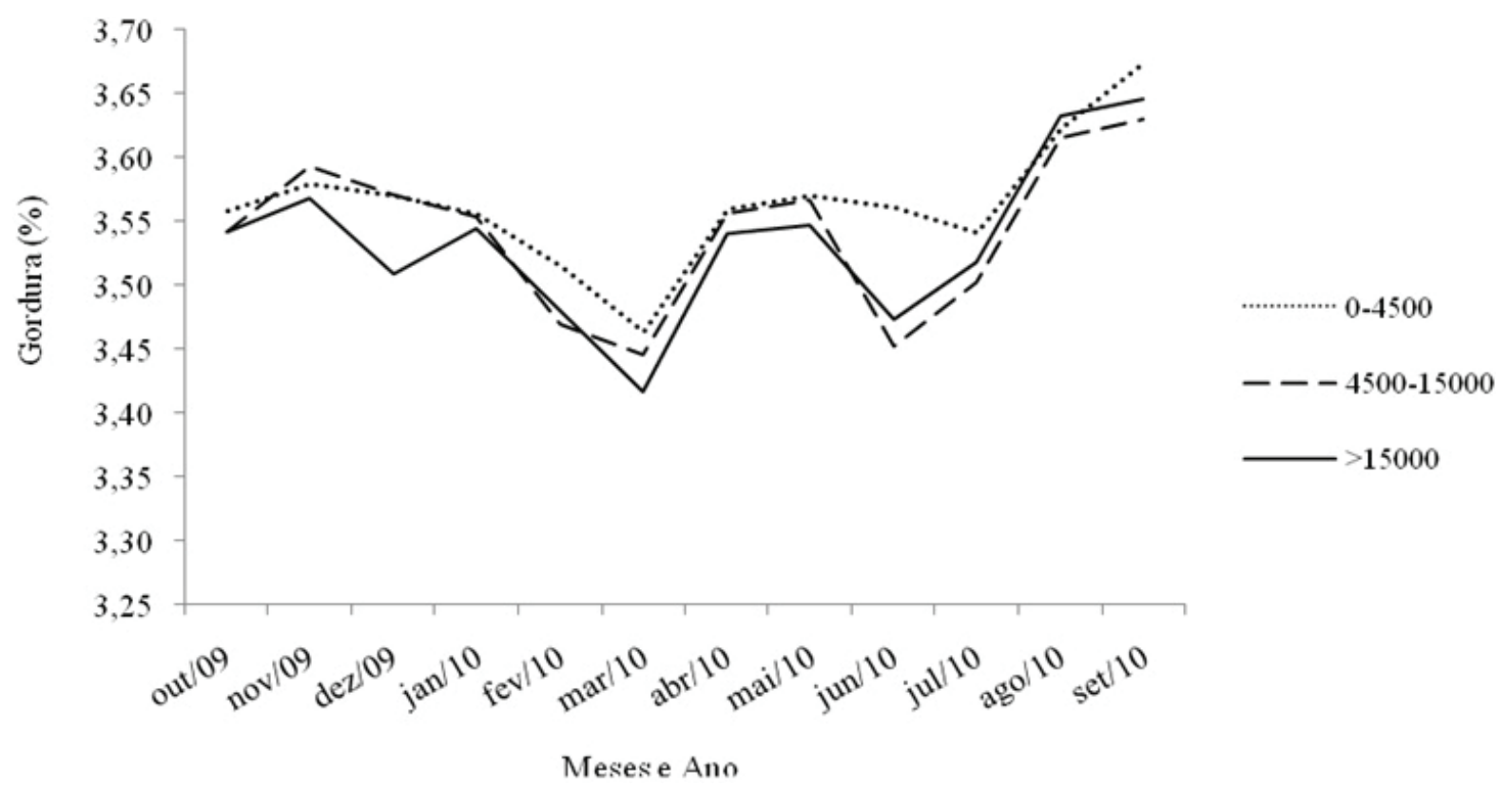

Fonte: Elaboração dos autores.

A maior proporção de concentrado na dieta das vacas lactantes auxilia a explicar o menor percentual de gordura no outono e no inverno. No outono devido a menor oferta de pastagens de verão e no inverno, pela maior oferta de concentrados em função do maior preço do leite e pelo pastejo na aveia, que possui menor teor de fibra que as pastagens de verão (Figura 3).

A CBT foi significativamente maior no leite oriundo de propriedades com volume até 4.500 litros mensais, seguida pelas com volume entre 4.500 a 15.000 litros mensais. A menor CBT foi obtida nas propriedadescom volume superior a quinze mil litros mensais (Tabela 3). A comparação entre CBT para tipos de resfriador e períodos do ano (Figura 4), resultou em interação significativa $(\mathrm{p}<0,0001)$.
A grande proporção de produtores com volume até 4.500 litros mensais com resfriador tipo imersão (Tabela 1) e ordenhadeira do tipo balde ao pé (Tabela 2) auxiliam a explicar níveis maiores de CBT. Estes resultados estão de acordo com os encontrados por Cordioli, Oldra e Schmitt Filho (2009) e Taffarel et al. (2013) em que, leite estocados em resfriadores a granel possuem menor CBT em relação a leite conservado em resfriador tipo imersão ou freezer; da mesma forma, leite oriundo de sistemas de ordenha canalizados possuem menor CBT em relação ao leite oriundo de ordenha manual ou balde ao pé.

O resfriamento é o principal fator responsável pelo padrão microbiológico do leite e o correto dimensionamento e funcionamento do sistema de resfriamento é uma condição importante para 
manter a CBT baixa. Um adequado resfriamento do leite a uma temperatura de $4^{\circ} \mathrm{C}$ em até duas horas após a ordenha associado a boas práticas de higienização produzem sinergia na redução da CBT (SCABIN et al., 2012; FAGUNDES et al., 2006).

Figura 4. Contagem bacteriana total do leite de acordo com o tipo de resfriador no período de outubro de 2009 a setembro de 2010 (interação CBT x tipo de resfriador x períodos do ano $\mathrm{p}<0,0001$; CV=143,78\%).

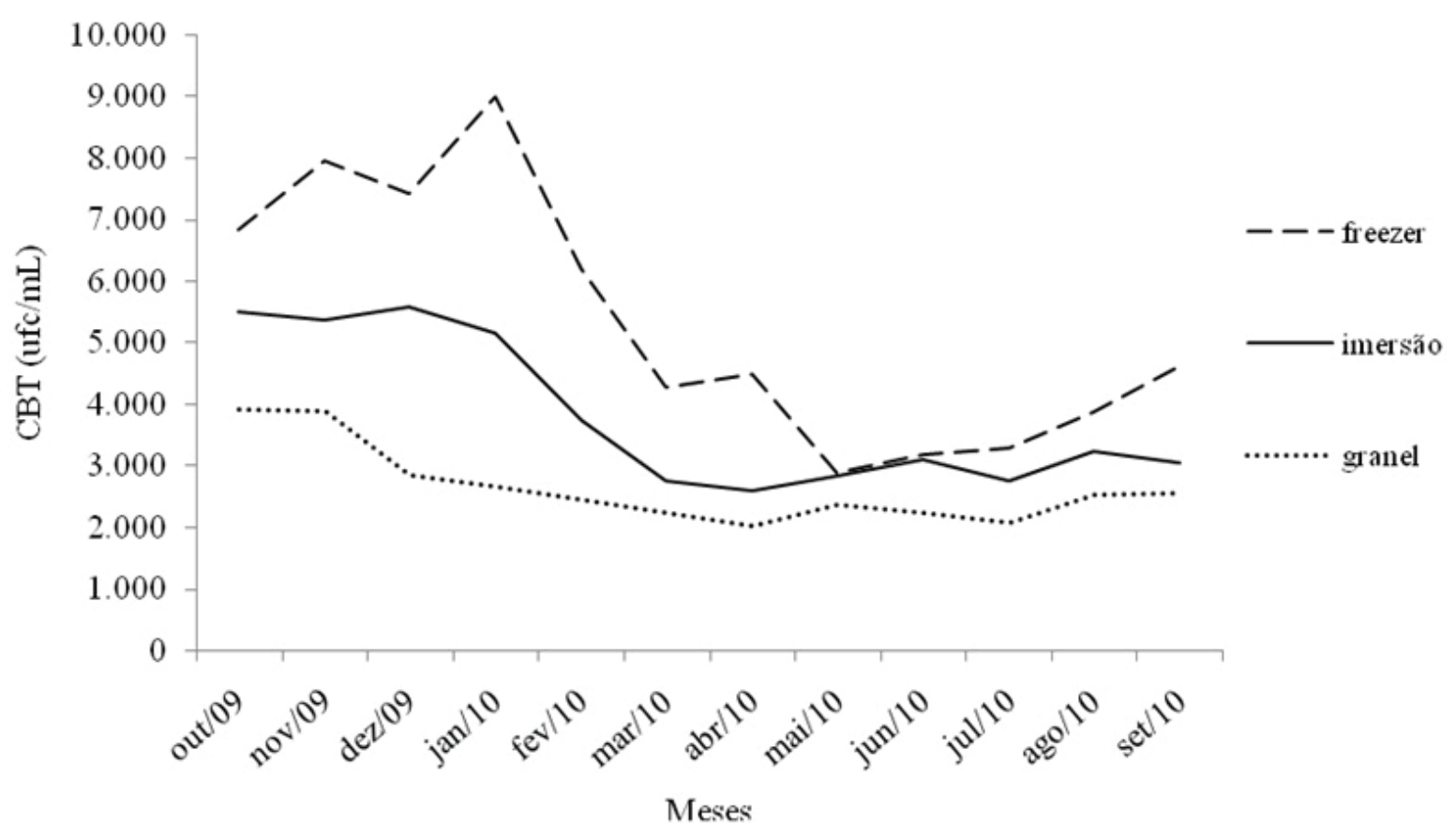

Fonte: Elaboração dos autores.

É provável que a maior CBT do leite resfriado em freezer e imersão (Figura4) seja devido à incapacidade de resfriamento a $4^{\circ} \mathrm{C}$ após duas horas da ordenha e a maior dificuldade de higienização, devido as maiores temperaturas e precipitação nos meses de outubro de 2009 a abril de 2010 (Figura1). Esses resultados (Figura 4) estão de acordo com os encontrados por Taffarel et al. (2013) em que o leite com menor CBT foi aquele oriundo de resfriadores a granel.

Houve interação significativa $(p=0,0423)$ na comparação entre resultados de CBT e sistemas de ordenha $(2,77 \%$ manual, $76,95 \%$ balde ao pé, $16,3 \%$ canalizada e $3,97 \%$ transferidor das propriedades) emeses do ano (Figura 5). A CBT do leite oriundo da ordenha manual e balde ao pé foi maior que a CBT do leite oriundo de ordenha canalizada e de ordenha com transferidor durante os 12 meses estudados (Figura 5) e estão de acordo com os encontrados por Taffarel et al. (2013).Existem diversos fatores envolvidos para a alta CBT, como os fatores ambientais (Figura 1), entretanto, relaciona-se como a maior causa a baixa utilização de práticas simples como desprezo dos três primeiros jatos de leite, lavagem dos utensílios de ordenha (latões, baldes, teteiras) com detergente alcalino clorado $2 \%$, pré-dipping com solução clorada 750 ppm em caneca sem refluxo e eliminação da água residual dos utensílios de ordenha, como recomendaram Vallin et al. (2009).

Na região Oeste do Paraná, destaca-se ainda que $82,3 \%$ fazem a higienização dos tetos de 
forma inadequada e 4,1\% não o fazem, sendo que apenas $12,7 \%$ utilizam produtos recomendados para desinfecção do equipamento de ordenha (IPARDES, 2009). Uma pesquisa realizada na microrregião de Marechal Cândido Rondon revelou que apenas42\% dos produtores sabem a frequência correta de pulsações por minuto da ordenhadeira e $45 \%$ sabem a temperatura adequada para higienização do equipamento de ordenha e a cada quanto tempo deve-se trocar as teteiras (TAFFAREL et al., 2012).

Figura 5. Contagem bacteriana total do leite de acordo com o sistema de ordenha utilizado no período de outubro de 2009 a setembro de 2010(interação CBT x Sistemas de Ordenha x Períodos do ano p=0,0423; CV = 143,95\%).

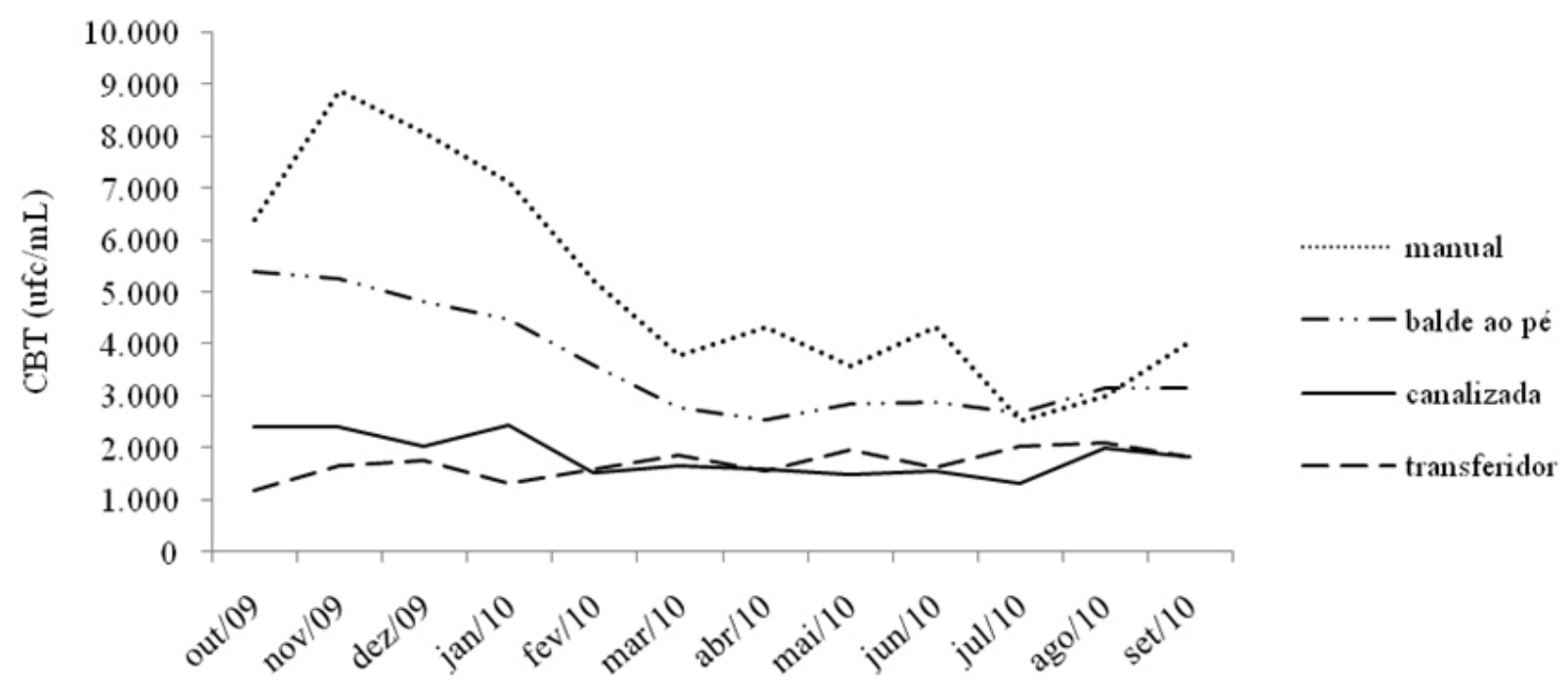

Fonte: Elaboração dos autores.

A utilização de técnicas adequadas de higiene da ordenha é uma estratégia para a melhoria da qualidade bacteriológica do leite (CAVALCANTI et al., 2010). O uso de detergentes alcalino e ácido e sanitizantes estão associados a contagens bacterianas inferiores a $100 \mathrm{mil} \mathrm{UFC} / \mathrm{mL}$, enquanto a utilização de apenas um ou de nenhum produto está associado a contagens superiores a $500 \mathrm{mil} \mathrm{UFC/mL} \mathrm{(ARCURI} \mathrm{et} \mathrm{al.,} \mathrm{2006).} \mathrm{Esses}$ autores concluíram que a adoção de procedimentos adequados de limpeza dos equipamentos de ordenha e estocagem do leite contribui para a redução da contagem de mesófilos do leite.

O maior $(\mathrm{p}<0,0001)$ índice de células somáticas (935.340 cel./mL) foi alcançado pelos produtores com produção entre 4501 a 15000 litros mensais em relação as faixas de menor e maior volume mensal
(Tabela 3). Não houve diferenças $(p=0,91)$ entre tipos de resfriadores e CCS, entretanto ocorreu significância $(p<0,0001)$ entre CCS e períodos do ano, mas não houve interação $\operatorname{CCS} \mathrm{x}$ tipos de resfriadores x períodos do ano (Figura 6).

Cordioli, Oldra e Schmitt Filho (2009) concluíram que uma menor CCS está mais relacionada a secagem das vacas 60 dias antes do parto. Entretanto, alta CCS é mais frequentemente relatada como indicativo e relação direta com maior prevalência de mastite, riscos de contaminação de leite por antibióticos e probabilidade de ocorrência de bactérias patogênicas (PALES et al., 2005).

Entre as bactérias patogênicas mais associadas à mastite e a alta CCS, destacamse principalmente Staphylococcus aureus, 
Streptococcusdysgalactiae, Streptococcusuberis, Enterococcus spp., Escherichia coli, Pseudomonas spp. e fungos e, essa associação está negativamente correlacionada a gordura do leite, proteína e lactose (PARK et al., 2007).
Assim, um dos primeiros impactos que pode ser considerado com a alta CCS encontrada é a perda da produção de leite, além das alterações na composição do leite em decorrência da mastite e suas consequências sobre a produção de produtos lácteos (GIGANTE; COSTA, 2008).

Figura 6. Contagem de células somáticas do leite de acordo com o sistema de resfriamento utilizado no período de outubro de 2009 a setembro de 2010(CCS x Tipos de resfriadores $\mathrm{p}=0,91$; CCS x Períodos do ano $\mathrm{p}<0,0001$; CCS x Tipos de resfriadores $\mathrm{x}$ Períodos do ano $\mathrm{p}>0,05 ; \mathrm{CV}=89,85 \%$ ).

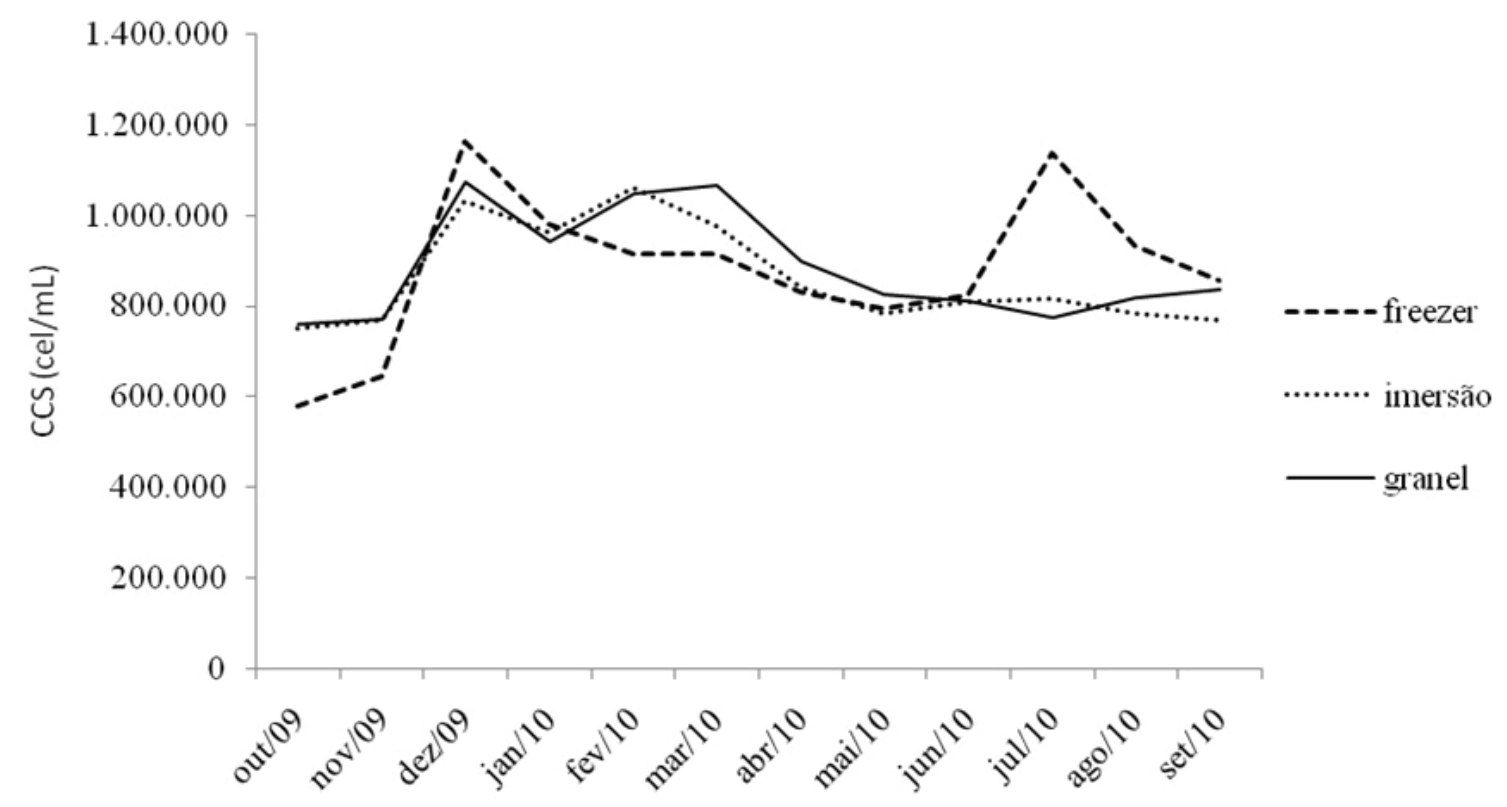

Fonte: Elaboração dos autores.

A má qualidade do leite cru em decorrência de alta CBT e alta CCS está relacionada com fatores como deficiências no manejo e higiene da ordenha, índices elevados de mastite, manutenção e desinfecção inadequada dos equipamentos de ordenha e resfriamento, refrigeração ineficiente e mão de obra desqualificada, entre outros (VALLIN et al., 2009).

A higienização e desinfecção adequada podem ser prejudicadas se o ambiente onde as vacas permanecem ou dormem tem excesso de barro, o que leva a aumentara ocorrência de mastites. Esta hipótese auxilia a explicar os índices mais elevados de CCS durante o período de maior precipitação e temperaturas mais elevadas (Figura 1), independentemente do tipo de resfriamento (Figura 6) ou sistema de ordenha (Figura 7), pois o percentual de salas de ordenha ainda é baixo no Oeste do Paraná (IPARDES, 2009).

Quando comparamos resultados da CCS com tipos de ordenhas e períodos do ano não ocorreram interações significativas $(p=0,9999)$, entretanto, houve efeito dos períodos $(p=0,0001)$ e do tipo de ordenha $(p=0,0561)$ (Figura 7). Atribuiu-se a menor CCS no período de maio a setembro/2010 em função da menor temperatura e precipitação (Figura 1). Mesmo assim, os valores são considerados altos, o que demonstra que existem outros fatores que 
interferem na alta CCS.

$\mathrm{O}$ adequado funcionamento da ordenhadeira interfere sobre a incidência de novos casos de mastite e desta forma, o aumento da CCS, principalmente por diferenças de pressão e o número de pulsações (BARBOSA; BENEDETI;
GUIMARÃES，2009). Taverna (2004) relatou estudos em que altas flutuações irregulares e cíclicas aumentaram a frequência de mastite entre 47,5 a $60 \%$, deslizamentos de teteiras aumentaram entre 43 a $84 \%$ a frequência de novas infecções, retirada agressiva da teteira aumentou em $60 \%$ as novas infecções.

Figura 7. Contagem de células somáticas do leite de acordo com o sistema de ordenha utilizado no período de outubro de 2009 a setembro de 2010 (CCS x Períodos do ano $p=0,0001$; CCS x Sistemas de Ordenha $p=0,0561$; interação CCS $\mathrm{x}$ Períodos do ano $\mathrm{x}$ Sistemas de Ordenha $\mathrm{p}=0,9999 ; \mathrm{CV}=89,91 \%$ ).

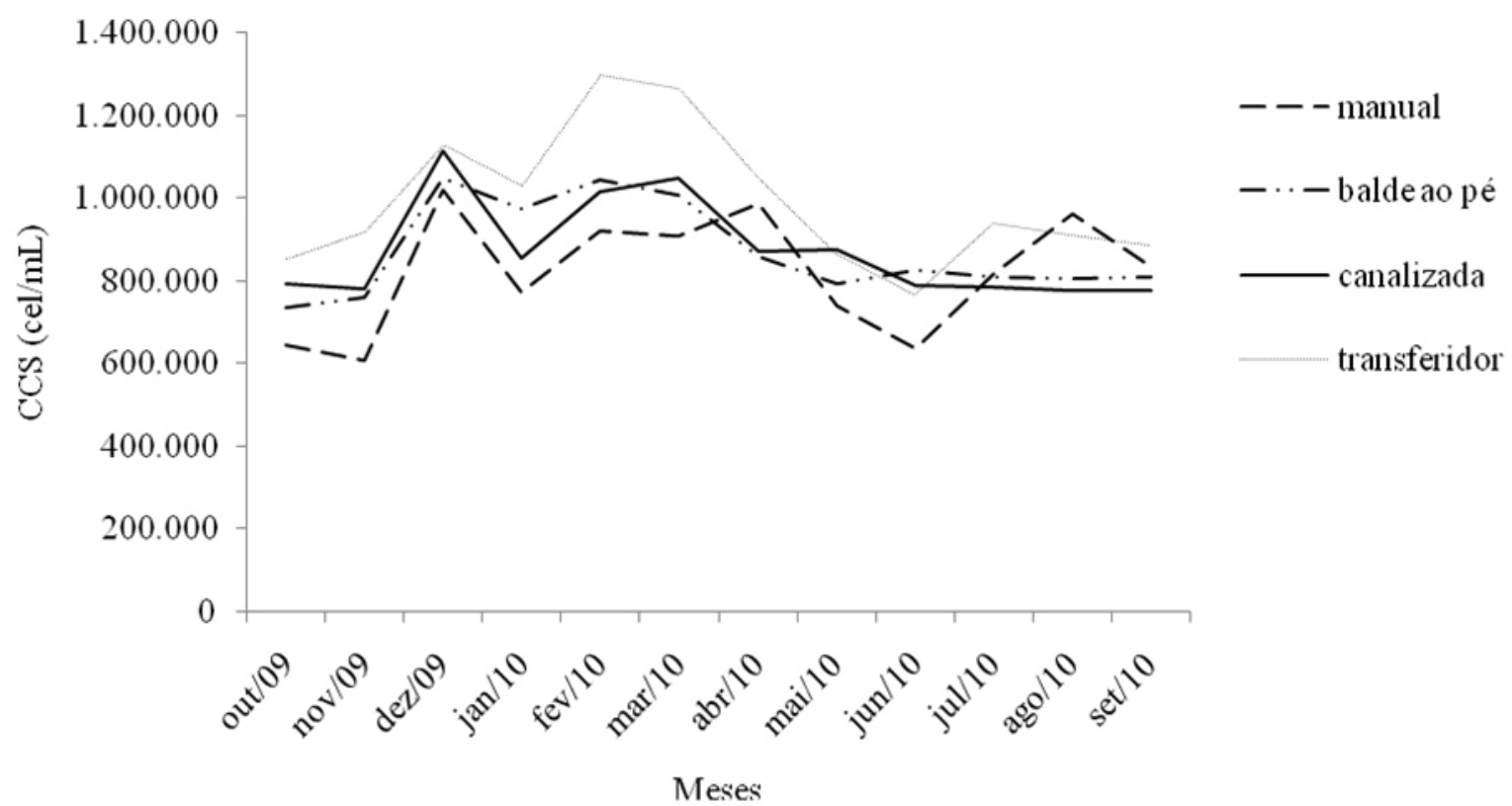

Fonte: Elaboração dos autores.

Taffarel et al. (2012) afirmaram que 55\% das ordenhadeiras possuíam entradas de ar em trabalho realizado na região Oeste do Paraná e 64\% com frequência de ordenha superior a 60 ciclos por minuto. Entradas de ar podem ser causadas por fissuras nas borrachas das teteiras que facilitam o acúmulo de leite, a aderência no teto (COENTRÃO et al., 2008) e também elevam as infecções na glândula mamária e aumentam a CCS (MEIN et al., 2004). Já frequências superiores a 60 ciclos provocam a sobre-ordenha e lesões nos tetos, que predispõem a mastite e aumento da CCS (MULLER, 2002).

\section{Conclusões}

O leite oriundo de produtores com volumes superiores a quinze mil litros mensais possui menor ponto crioscópico, teor de gordura, contagem bacteriana total e contagem de células somáticas.

Ocorrem variações estacionais do ponto de congelamento, teor de gordura, contagem bacteriana total e da contagem de células somáticas.

As variações da contagem bacteriana total durante os períodos do ano são menores no leite oriundo de resfriamento a granel e de ordenhadeiras canalizadas. 
Existem fatores relacionados ao manejo dos animais e higienização dos equipamentos de ordenha e resfriamento que necessitam ser trabalhados junto aos produtores.

\section{Referências}

ARCURI, E. F.; BRITO, M. A. V. P.; BRITO, J. R. F.; PINTO, S. M.; ANGELO, E. F.; SOUZA, G. N. Qualidade microbiológica do leite refrigerado nas fazendas. Arquivo Brasileiro de Medicina Veterinária e Zootecnia, Belo Horizonte, v. 58, n. 3, p. 440-446, 2006.

BARBOSA, C. P.; BENEDETTI, E.; GUIMARÃS, E. C. Incidência de mastite em vacas submetidas a diferentes tipos de ordenha em fazendas leiteiras na região do triângulo mineiro. Bioscience Journal, Uberlândia, v. 25, n. 6, p. 121-128, 2009.

BECCHI, C. S. Estudo do índice crioscópico do leite tipo $B$ "in natura" produzido na bacia leiteira do Vale do Taquari, RS. 2003. Dissertação (Mestrado em Ciências Veterinárias) - Universidade Federal do Rio Grande do Sul, Faculdade de Veterinária. Porto Alegre.

BORGES, K. A.; PINTO, A. T. Variações do índice crioscópico de amostras de leite recebidas na plataforma de um laticínio, no periodo de janeiro a agosto de 2007. In: CONGRESSO BRASILEIRO DE MEDICINA VETERINÁRIA, 35., 2008, Gramado - RS. Anais... Gramado: SOVERGS, 2008. Disponível em: <http:// www.sovergs.com.br/conbravet2008/anais/cd/resumos/ R0092-2.pdf $>$. Acesso em: 20 jul. 2012.

BOTARO, B.; SANTOS, M. V. Entendendo a variação da crioscopia do leite. Milkpoint, Piracicaba, 04 ago. 2008. Disponível em: <http://www.milkpoint.com.br/ radar-tecnico/qualidade-do-leite/entendendo-a-variacaoda-crioscopia-do-leite-46948n.aspx>. Acesso em: 20 jul. 2012.

CAVALCANTI, E. R. C.; CAVANCANTI, M. A. R.; SOUZA, W. J.; ARAÚJO, D. G. Avaliação microbiológica em ordenhadeira mecânica antes e após adoção de procedimento orientado de higienização. Revista Brasileira de Ciências Veterinárias, Niterói, v. 17, n. 1, p. 3-6, 2010.

COENTRÃO, C. M.; SOUZA, G. N.; BRITO, J. R. F.; PAIVA E BRITO, M. A. V.; LILENBAUM, W. Fatores de risco para mastitesubclínica em vacas leiteiras. Arquivo Brasileiro de Medicina Veterinária e Zootecnia, Belo Horizonte, v. 60, n. 2, p. 283-288, 2008.

CORDIOLI, E.; OLDRA, A.; SCHMITT FILHO, A. L. Sistemas de produção de leite e qualidade do produto final na agricultura familiar. Revista Brasileira de Agroecologia, Cruz Alta, v. 4, n. 2, p. 4493-4496, 2009.

FAGAN, E. P.; TAMANINI, R.; FAGNANI, R.; BELOTI, V.; BARROS, M. A. F.; JOBIM, C. C. Avaliação de padrões físico-químicos e microbiológicos do leite em diferentes fases de lactação nas estações do ano em granjas leiteiras no Estado do Paraná- Brasil. Semina: Ciências Agrárias, Londrina, v. 29, n. 3, p. 651-660, 2008.

FAGUNDES, C. M.; FISCHER, V.; SILVA, W. P.; CARBONERA, N.; ARAÚJO, M. R. Presença de Pseudomonas spp em função de diferentes etapas da ordenha com distintos manejos higiênicos e no leite refrigerado. Ciência Rural, Santa Maria, v. 36, n. 2, p. 568-572, 2006.

GIGANTE, M. L.; COSTA, M. R. Influências das células somáticas nas propriedades tecnológicas do leite e derivados. In: BARBOSA, S. B. P.; BATISTA, A. M. V.; MONARDES, H. In: CONGRESSO BRASILEIRO DE QUALIDADE DO LEITE, 3., 2008, Recife. Anais... Recife: CCS Gráfica e Editora, 2008. v. 1, p. 161-174.

GONZALEZ, F. H. D.; CAMPOS, R. Indicadores metabólico-nutricionais do leite. In: GONZÁLEZ, F. H. D.; CAMPOS, R. (Ed.). SIMPÓSIO DE PATOLOGIA CLÍNICA VETERINÁRIA DA REGIÃO SUL DO BRASIL, 1., 2003, Porto Alegre. Anais... Porto Alegre: Gráfica da Universidade Federal do Rio Grande do Sul, 2003. p. 31-47.

HENNO, M.; OTS, M.; JÕUDU, I.; KAART, T.; KÄRT, O. Factors affecting the freezing point stability of milk from individual cows. International Dairy Journal, Alberta, v. 18, p. 210-215, 2008.

INSTITUTO PARANAENSE DE DESENVOLVIMENTO ECONÔMICO E SOCIAL IPARDES. Caracterização socioeconômica da atividade leiteira do Paraná: sumário executivo. Curitiba: IPARDES, 2009. 29 p.

MARTINS, P. C.; YAMAGUCHI, L. C. T.; ARCURI, P. B.; ARCURI, E. F. O compromisso com a qualidade do leite no Brasil: In:__. Pagamento por qualidade no Brasil: motivações e obstáculos. Passo Fundo: UPF, 2004. p. 87-104.

MEIN, G.; REINEMANN, D.; SCHURING, N.; OHNSTAD, I. Milking machines and mastitis risk: a storm in a teatcup. In: NATIONAL MASTITIS COUNCIL ANNUAL MEETING, 43., 2004, Charlotte. Proceedings... Charlotte: NMC, 2004. p. 176-188.

MONTIPÓ, R. B. Determinação do ponto de congelamento do leite bovino "in natura" da bacia leiteira de Santa Maria-RS. 1992. Dissertação (Mestrado 
em Zootecnia) - Universidade Federal de Santa Maria, Santa Maria.

MULLER, E. E. Qualidade do leite, células somáticas e prevenção da mastite. In: SUL - LEITE: SIMPÓSIO SOBRE SUSTENTABILIDADE DAPECUÁRIA LEITEIRA NA REGIÃO SUL DO BRASIL, 2., 2002, Maringá. Anais... Maringá: UEM/CCA/DZO, 2002, p. 206-217.

PALES, A. P.; SANTOS, K. J. G.; FIGUEIRAS, E. A.; MELO, C. S. A importância da contagem de células somáticas e contagem bacteriana total para melhoria da qualidade do leite no Brasil. Revista Eletrônica Faculdade Montes Belos, São Luis de Montes Belos, v. 1, n. 2, p. 162-173, 2005.

PARK, Y. K.; KOO, H. C.; KIM, S. H.; HWANG, S. Y.; JUNG, W. K.; KIM, J. M.; SHIN, S.; KIM, R. T.; PARK, Y. H. The analysis of milk componentes and pathogenic bactéria isolated from bovine raw milk in Korea. Journal of Dairy Science, Champaign, IL, v. 90, n. 12, p. 54055414, 2007.

PYÖRÄLÄ, S. New strategies to prevent mastitis. Reproduction in Domestic Animals, Malden, v. 37, n. 4, p. 211-116, 2002.

REIS, G. L.; ALVES, A. A.; LANA, A. M. Q.; COELHO, S. G.; SOUZA, M. R.; CERQUEIRA, M. M. O. P.; PENNA, C. F. A. M.; MENDES, E. D. M. Procedimentos de coletade leite cru individual e sua relação com a composição físico-química e a contagem de células somáticas. Ciência Rural, Santa Maria, v. 37, n. 4, p. 1134-1138, 2007.

RIBAS, N. P.; HARTMANN, W.; MONARDES, H. G.; ANDRADE, U. V. C. Sólidos totais do leite em amostras de tanques nos Estados do Paraná, Santa Catarina e São Paulo. Revista Brasileira de Zootecnia, Viçosa, MG, v. 33, n. 6, p. 2343-2350, 2004. Suplemento 3.

ROMA JÚNIOR, L. C.; MONTOYA, J. F. G.; MARTINS, T. T.; CASSOLI, L. D.; MACHADO, P. F. Sazonalidade do teor de proteína e outros componentes do leite e sua relação com programa de pagamento por qualidade. Arquivo Brasileiro de Medicina Veterinária e Zootecnia, Belo Horizonte, v. 61, n. 6, p. 1411-1418, 2009.
SAS INSTITUTE. SAS user's guide: statistics, version 9.0. Cary: SAS Institute, 2002.

SCABIN, K. E. M.; KOZUSNY-ANDREANI, D. I.; FRIAS, D. F. R. Microbiological quality of milk in nature during the process of obtaining and after cooling. Revista CES Medicina Veterinaria y Zootecnia, Medellin, Colombia, v. 7, n. 1, p. 11-21, 2012.

TAFFAREL, L. E.; COSTA, P. B.; OLIVEIRA, N. T. E.; BRAGA, G. C.; ZONIN, W. J. Contagem bacteriana total do leite em diferentes sistemas de ordenha e de resfriamento. Arquivos do Instituto Biológico, São Paulo, v. 80, n. 1, p. 7-11, 2013.

TAFFAREL, L. E.; COSTA, P. B.; TSUTSUMI, C.; TODERO, E. J.; CAVILHÃO, C.; PIRES, S. C. Manutenção de ordenhadeiras em propriedades familiares do Oeste do Paraná. Revista UDESC em Ação, Florianópolis, v. 6, n. 1, p. 1-12, 2012.

TAKAHASHI, F. H.; CASSOLI, L. D.; ZAMPAR, A.; MACHADO, P. F. Variação e monitoramento da qualidade do leite através do controle estatístico de processos. Ciência Animal Brasileira, Goiania, GO, v. 13, n. 1, p. 99-107, 2012.

TAVERNA, M. Tecnologia de ordenha e qualidade do leite. In: DURR, J. W.; CARVALHO, M. P.; SANTOS, M. V. O compromisso com qualidade do leite. Passo Fundo: Editora UPF, 2004. v. 1, p. 146-177.

TRONCO, V. M. Controle físico-químico do leite. In: . Manual para inspeção da qualidade do leite.

Santa Maria: UFSM, 1997. cap. V, p. 103-105.

VALLIN, V. M.; BELOTI, V.; BATTAGLINI, A. P. P.; TAMANINI, R.; FAGNANI, R.; ANGELA, H. L.; SILVA, L. C. C. Melhoria da qualidade do leite a partir da implantação de boas práticas de higiene na ordenha em 19 municípios da região central do Paraná. Semina: Ciências Agrárias, Londrina, v. 30, n. 1, p. 181-188, 2009.

ZECCONI, A.; HAMANN, J.; BRONZO, V.; MORONI, P.; GIOVANNINI, G.; PICCININI, R. Relationship between teat tissue immune defences and intramammary infections. Advances in Experimental Medicine and Biology, New York City, v. 480, n. 33, p. 287-293, 2002. 
